\title{
SÍNTESE DE CELULASE POR CULTIVO EM ESTADO SÓLIDO: OTIMIZAÇÃO DO PROCESSO DE EXTRAÇÃO
}

\author{
L. PINTO ${ }^{1}$, L. C. T. CARVALHO ${ }^{2}$, E. J. F. CHAVES ${ }^{2}$, K. S. BONFIM ${ }^{1}$, D. A. M. de \\ ARAÚJO $^{2}$ e S. F. de M. SANTOS ${ }^{1}$ \\ ${ }^{1}$ Universidade Federal da Paraíba, Departamento de Engenharia Química \\ ${ }^{2}$ Universidade Federal da Paraíba, Departamento de Biotecnologia \\ E-mail para contato: sharlinefm@hotmail.com
}

\begin{abstract}
RESUMO - O objetivo deste trabalho foi analisar a produção de celulases por três fungos isolados do solo da Usina Japungu, no município de Santa Rita - PB, bem como verificar as melhores condições para a sua extração, por meio da metodologia do planejamento experimental fatorial. Os cultivos foram realizados em duplicata para cada fungo, utilizando $90 \mathrm{~g}$ de farelo de trigo, com $50 \%$ de umidade, em frascos de $1000 \mathrm{~mL}$. O meio foi inoculado com os fungos na concentração de $10^{6}$ esporos por grama de meio e incubados a $35^{\circ} \mathrm{C}$, durante 6 dias. A cada dia de cultivo uma amostra era retirada para análise da atividade de CMCase. O fungo FSDE 15 demonstrou ser o melhor produtor de celulases com atividade de 6,198 U/g em 96 horas. O processo de otimização da extração enzimática do fungo FSDE15 utilizou as seguintes variáveis para análise: tempo de contato com o solvente, temperatura, velocidade de agitação e razão volume de solvente por massa do cultivo. A atividade celulolítica encontrada variou de 1,244 a 7,914 U/g. Desta forma, a atividade enzimática máxima, de 7,914 U/g, foi obtida a partir das seguintes condições: 35 minutos, $40^{\circ} \mathrm{C}, 150 \mathrm{rpm}$, e razão de $11 \mathrm{~mL} / \mathrm{g}$.
\end{abstract}

\section{INTRODUÇÃO}

Durante vários anos os combustíveis fósseis foram utilizados como a principal fonte de energia da economia mundial, no que diz respeito ao transporte, uso doméstico e industrial. Isso ocorreu principalmente devido ao baixo custo, com relação a outras fontes de energia, mas essa situação se mostrou ilusória tendo em vista que o seu consumo tem aumentado exponencialmente nos últimos anos. Como suas reservas são esgotáveis, nas ultimas décadas a sociedade tem direcionado bastante atenção aos combustíveis renováveis por ser uma fonte alternativa com maior projeção de reservas do que os combustíveis fósseis, além disto, com menor impacto ambiental (Grochmann, 1988).

A produção de combustíveis a partir de materiais lignocelulósicos surge como uma opção bastante atraente, sobretudo no cenário nacional, uma vez que os resíduos agroindustriais como, por exemplo, o bagaço e a palha da cana-de-açúcar, são abundantemente disponíveis no atual sistema produtivo de açúcar e etanol no Brasil. 


\section{9 a 22 de outubro de 2014 \\ Florianópolis/SC}

Dentre os biocombustíveis mais estudados nos últimos anos destaca-se o bioetanol. A produção de bioetanol com base em biomassas lignocelulósicas precisa de processos químicos ou bioquímicos para converter a celulose em açúcares fermentescíveis. Os processos químicos têm a vantagem de envolver uma tecnologia mais avançada, mas possui desvantagens como ser de difícil controle para evitar possível degradação dos açúcares e formação de inibidores.

Nos processos bioquímicos, a conversão da celulose/hemicelulose, em açúcares é catalisada por enzimas. A tecnologia de hidrolise enzimática apresenta grande potencial em virtude de características como elevada especificidade da reação, ausência de reações secundárias, ausência de produtos secundários (inibidores da fermentação alcoólica) e operação em condições suaves de temperatura e pressão (Chang, 2014; Grochmann, 1988).

Os biocatalisadores utilizados no processo hidrolítico são, na verdade, enzimas altamente específicas chamadas de celulases: endoglucanases, que clivam randomicamente as ligações internas da região amorfa, liberando oligossacarídeos com terminações redutoras e não redutoras livres; exoglucanases, subdivididas em celobiohidrolases (CBHs) que são responsáveis pela hidrólise dos terminais redutores (CBHs do tipo I) e não redutores (CBHs do tipo II), e glucanohidrolases (GHs), capazes de liberar moléculas de glicose diretamente dos terminais do polímero; e $\beta$-glucosidases, que hidrolisam a celobiose e os oligossacarídeos solúveis de baixo grau de polimerização (menor que 7) a glicose. Uma importante característica das enzimas do complexo celulósico é a forte inibição que essas moléculas sofrem pelo produto (glicose) da reação que catalisam (Murphya et al., 2013).

Um dos fatores que mais impacta na viabilidade econômica do processo de produção de etanol a partir de biomassas lignocelulósicas mediante hidrólise enzimática é o alto custo da enzima que pode representar até 18\% do custo da planta (Castro e Pereira Jr, 2010). Isto mostra a importância da necessidade de se desenvolver procedimentos que reduzam custos de produção desta enzima, utilizando principalmente resíduos industriais como é o caso do bagaço de cana-deaçúcar, farelo de milho, farelo de trigo, entre outros.

O objetivo deste trabalho foi avaliar a produção de celulases por três fungos filamentosos, isolados do solo da Usina Japungu, no município de Santa Rita - Paraíba, bem como otimizar o processo de extração das celulases por meio da metodologia do planejamento experimental fatorial.

\section{MÉTODOLOGIA}

\subsection{Micro-organismos}

Os três fungos filamentosos (FSDE3, FSDE15 e FSP8) utilizados neste estudo foram previamente selecionados por meio do crescimento dos mesmos em placas de Petri contendo o meio mineral de Mandels e Weber (1969), com adição de ágar (1,5\%) e carboximetilcelulose $(1 \%)$, por 4 dias a $37^{\circ} \mathrm{C}$. A presença de um halo de hidrólise, ao redor da colônia, indicou a produção de celulases pelo micro-organismo, após as placas serem coradas com uma solução de 
vermelho congo $0,1 \%$ e, posteriormente, lavadas com $\mathrm{NaCl} 1 \mathrm{M}$ (Figura 1). Os fungos utilizados neste estudo foram aqueles que apresentaram o maior índice enzimático.
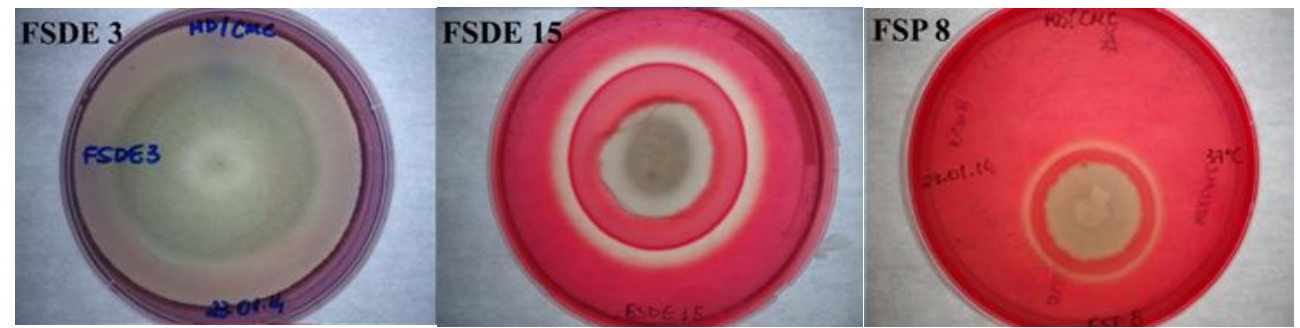

Figura 1- Presença do halo de hidrólise da carboximetilcelulose pelos fungos.

Para obtenção do inóculo foi feito o repasse dos fungos do estoque para placas de petri contendo o meio BDA (Batata Dextrose Ágar). As placas foram incubadas em estufa por 5 dias a $37^{\circ} \mathrm{C}$, após o crescimento, os esporos foram suspensos em água destilada estéril. Para obter a concentração desejada de $10^{6}$ esporos/g foi feita a contagem de esporos utilizando a câmara de Neubauer no microscópio eletrônico. Assim o volume de inóculo foi obtido pela Equação 1:

$$
\text { Volume do inóculo }_{(m L)}=\frac{\text { Conc. esporos desejada }\left(\frac{\text { esporos }}{g}\right) * \text { Massa substrato } g}{\text { Conc.de esporos }\left(\frac{\text { esporos }}{m L}\right)}
$$

Onde:

Conc. esporos desejada $($ esporos $/ g)=10^{6}$ esporos $/ g$; Massa substrato $=90 \mathrm{~g}$

\subsection{Cultivo}

Os micro-organismos foram cultivados em meio sólido, contendo farelo de trigo como fonte de carbono, em erlenmeyer de $1000 \mathrm{~mL}$, com 90 gramas de farelo de trigo com umidade de $50 \%$, umedecido com meio mineral de Mandels e Weber (1969).

Para ajustar a umidade do meio de cultivo primeiro foi determinada a umidade do farelo de trigo. A determinação da umidade do farelo de trigo foi realizada em estufa a $105{ }^{\circ} \mathrm{C}$, durante 24 horas, conforme protocolo padrão (Brasil, 1992). Para obtenção do meio com 50\% de umidade, foi realizado o cálculo de massa de líquido a ser adicionada ao meio, por meio da Equação 2 proposta por Maciel (2006):

$$
m \mathrm{H}_{2} \mathrm{O}=\left(m s\left(\mathrm{X}_{2}-\mathrm{X}\right)\right) /\left(1-\mathrm{X}_{2}\right)
$$

Onde, $\mathrm{mH}_{2} \mathrm{O}=$ massa de água a ser adicionada; $\mathrm{ms}=$ massa de substrato seco; $\mathrm{X}_{1}=$ porcentagem inicial de umidade do substrato; $\mathrm{X}_{2}=$ porcentagem final de umidade desejada.

Após esterilização em autoclave, os micro-organismos foram inoculados com uma concentração de $10^{6}$ esporos/g. Os erlenmeyers foram incubados, em duplicata, a $37^{\circ} \mathrm{C}$, durante 6 
dias. A cada 24 horas de cultivo foram retirados 2 gramas do meio de cultivo para posterior extração e análise enzimática.

\subsection{Extração enzimática}

A cada grama de amostra meio sólido retirada, foram adicionadas $5 \mathrm{~mL}$ do solvente (tampão citrato de sódio, $50 \mathrm{mM}, \mathrm{pH} 4,8$ ). As amostras ficaram em contato com o solvente por 1 hora, a temperatura ambiente. Em seguida, os componentes sólidos foram separados por filtração, com papel de filtro Whatman $\mathrm{n}^{\mathbf{0}} 1$. O material filtrado foi utilizado para quantificação da atividade enzimática. Para determinação da atividade celulolítica, foi utilizado o procedimento recomendado por Ghose (1987), tendo como substrato a carboximetilcelulose (4\%), em tampão citrato de sódio $50 \mathrm{mM}, \mathrm{pH} 4,8$.

\subsection{Otimização da extração de celulases}

No último dia de cultivo foram utilizados quatro solventes distintos para a extração enzimática: tampão citrato de sódio $50 \mathrm{mM}$ pH 4,8; solução salina com cloreto de sódio $0,9 \%$, água destilada e água destilada com Tween 80 0,1\% (v/v). As amostras ficaram em contato com o solvente por 1 hora. A filtração e atividade enzimática foram realizadas de acordo com o tópico 2.2.

O solvente que demonstrou o maior potencial durante o processo de extração de celulases foi selecionado para otimização do processo de extração enzimática.

Os parâmetros selecionados para análise da extração foram estudados por meio de um planejamento fatorial completo $2^{4}$ acrescido de configuração estrela, cujas variáveis de entrada foram: tempo de extração, razão volume de solvente por massa de meio cultivado, temperatura do solvente e velocidade de agitação, com três repetições no ponto central de acordo com a Tabela 1 onde é mostrada as variáveis decodificadas.

Tabela 1 - Planejamento fatorial $2^{4}$ (condições de extração da enzima)

\begin{tabular}{c|ccccc|} 
Variáveis & $\mathbf{- 1}$ & $\mathbf{0}$ & $\mathbf{1}$ & $\boldsymbol{- \alpha}$ & $+\boldsymbol{\alpha}$ \\
\hline Tempo $(\mathbf{m i n})$ & 5 & 20 & 35 & 5 & 35 \\
Temperatura $\left({ }^{\circ} \mathbf{C}\right)$ & 20 & 30 & 40 & 20 & 40 \\
Velocidade $(\mathbf{r p m})$ & 100 & 150 & 200 & 100 & 200 \\
Razão $(\mathbf{m L} / \mathbf{g})$ & 5 & 8 & 11 & 5 & 11 \\
\cline { 2 - 6 }
\end{tabular}

\section{RESULTADOS E DISCUSSÃO}

Os fungos selecionados FSDE15, FSDE3 e FSP8 apresentaram bom crescimento no meio de farelo de trigo nas condições do cultivo, podendo ser visualizado crescimento logo após 24 
horas. De acordo com as análises de atividade de CMCase, realizadas a cada 24 horas de cultivo, podemos perceber que todos eles demonstraram produzir celulases, conforme mostrado na Figura 2.

O fungo FSDE15 se destacou entre os outros, por apresentar uma atividade de CMCase 6,198 U/g em 96 horas. O fungo FSDE3 também apresentou uma notável produção de celulases, 4,85 U/g, com 48 horas de cultivo (Figura 2).

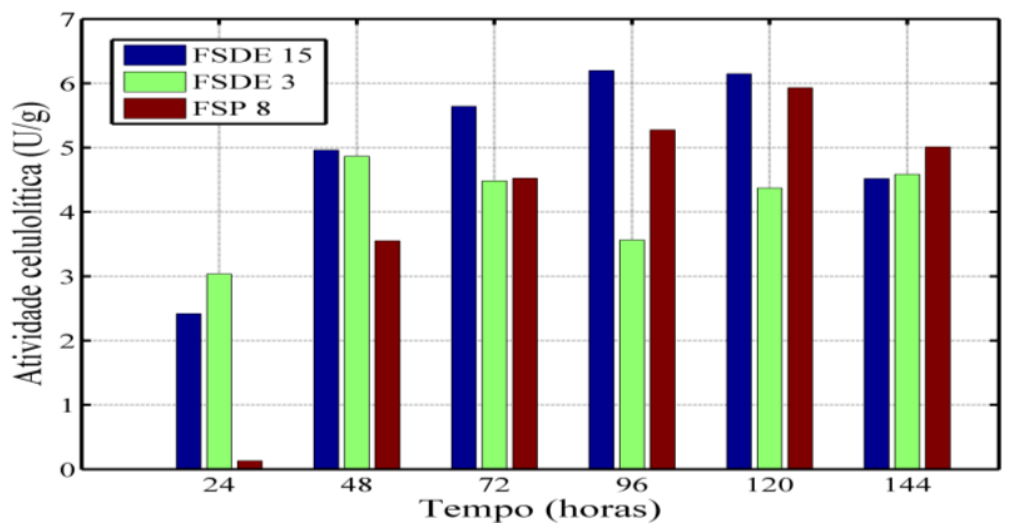

Figura 2 - Atividade celulolítica dos fungos isolados.

Uma vez que o fungo FSDE 15 apresentou a maior produção de atividade de celulases, ele foi selecionado para otimização do processo de extração enzimática. Inicialmente foram avaliados quatro solventes distintos, $\mathrm{NaCl} 0,9 \%$, Tween $0,1 \%$, Tampão Citrato pH4,8 e Água destilada, apresentando uma atividade celulolitica de 4,40;3,06; 4,26 e 3,70 respectivamente. Desta forma foi escolhido o cloreto de sódio $0,9 \%$ como o melhor solvente para realizar os ensaios de extração.

De acordo com Castilho et al. (1999), os fatores que mais influenciam a extração da enzima são o tipo de solvente, a relação sólido-líquido, a temperatura, a agitação, o tempo de contato e as relações entre todos esses fatores. Os valores de atividade de CMCase, obtidos nas condições de extração do planejamento, mostram uma grande variação (Atividade de CMCase variando de 1,244 a 7,914 U/g) o que indica que um planejamento para a extração desta enzima pode aumentar muito o rendimento final da produção da mesma.

Com os resultados do planejamento foi analisado o ajuste linear do modelo com interações de ordem 1, 2 e 3 entre os fatores estudados. Através do resultado da ANOVA pode-se perceber que o melhor ajuste é com interação de $3^{\mathrm{a}}$ ordem entre os fatores, pois apenas na interação de ordem 3 a regressão é significativa e a falta de ajuste não é significativa, simultaneamente, para 95\% de confiança, como mostrado na Tabela 2. 
Tabela 2 - ANOVA para o planejamento com interações de $3^{\mathrm{a}}$ ordem

\begin{tabular}{c|c|c|c|c|c|}
\cline { 2 - 5 } Fonte de Variação & $\begin{array}{c}\text { Soma } \\
\text { Quadrática }\end{array}$ & $\begin{array}{c}\text { Grau de } \\
\text { liberdade }\end{array}$ & $\begin{array}{c}\text { Média } \\
\text { Quadrática }\end{array}$ & F calc & F calc/ Fcrit \\
\hline Regressão & 62,515 & 14 & 4,465 & 188,497 & 9,704 \\
\hline Resíduos & 1,023 & 12 & 0,085 & & \\
\hline Falta de Ajuste & 0,975 & 10 & 0,098 & 4,117 & 0,212 \\
\hline Erro Puro & 0,047 & 2 & 0,024 & & \\
\hline Total & 63,538 & 26 & & & \\
\hline R- quadrado & 0,984 & & & & \\
\hline R- quadrado max & 0,999 & & & & \\
\hline
\end{tabular}

O valor das constantes do modelo criado para explicar os resultados experimentais para o planejamento está mostrado na Tabela 3. Com estes valores é possível construir a equação linear que melhor explica o modelo de extração. Vemos que os efeitos combinados não possuem uma influencia muito grande, o que podemos observar devido aos baixos valores dos coeficientes estimados. Da mesma forma podemos observar que a influencia dos parâmetros estudados é alta, pois os coeficientes estimados são altos em comparação com os coeficientes dos fatores combinados, podemos observar também que a ordem de influencia dos fatores principais são tempo, temperatura, velocidade e razão, respectivamente de forma decrescente.

Tabela 3 - Constantes estimadas do modelo criado para o planejamento

\begin{tabular}{lllllllllll}
\hline Constante & $-154,092$ & D:Razão & $-0,1214$ & AD & $-0,0192$ & CD & $-0,0018$ & ABC & 0,0007 \\
\hline A:Tempo_min & 17,323 & AA & $-0,0371$ & BC & $-0,0007$ & DD & 0,0531 & ABD & 0,0012 \\
\hline B:Temperatura_ & 0,2214 & AB & $-0,0291$ & BD & $-0,0007$ & AAB & 0,0000 & ACD & 0,0002 \\
\hline C:Velocidade_rpm & 0,1651 & AC & $-0,0078$ & CC & $-0,0003$ & AAC & 0,0000 & & \\
\hline
\end{tabular}

Há quatro fatores a serem otimizados, que resulta em uma superfície de resposta em 5 dimensões, mas como só se pode observar figuras em 3 dimensões optou-se por fixar os parâmetros principais, e avaliar visualmente a variação das duas respostas em conjunto nas quatro figuras. Embora a inspeção visual pela superfície da Figura 3 seja apenas para a variação de dois dos quatro fatores, para a determinação dos melhores parâmetros o software statgraphics avalia a variação em conjunto de todos os fatores significativos. 

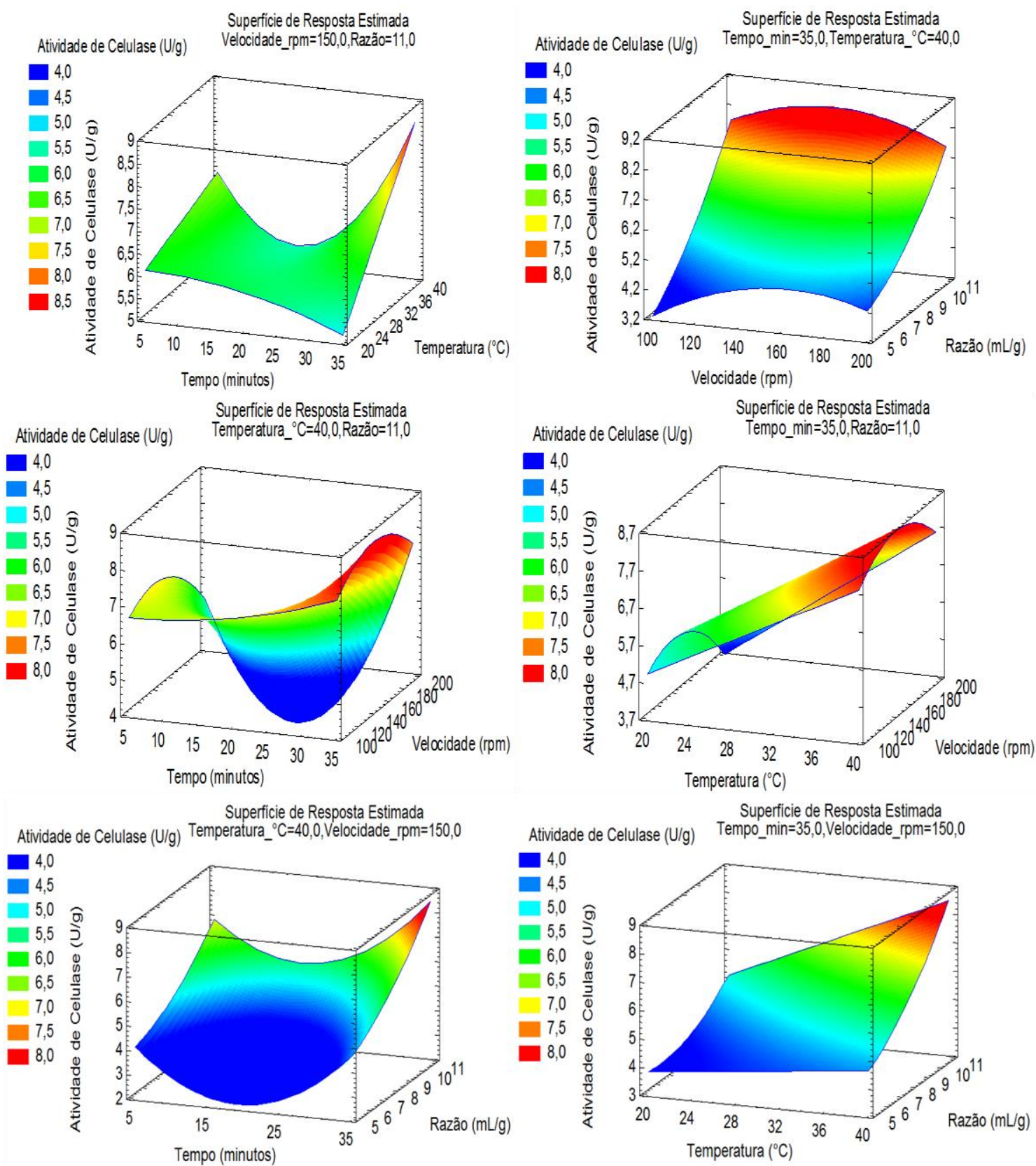

Figura 3. Superfícies de resposta para todos os 4 fatores principais estudados.

\section{CONCLUSÃO}

Neste estudo, avaliamos a produção de celulases por três fungos distintos isolados do solo. Todos eles demonstraram produzir celulases em meio de cultivo sólido, contendo farelo de 
trigo como fonte de carbono. Destes, o fungo FSDE 15 apresentou a maior atividade enzimática analisada. $\mathrm{O}$ melhor solvente indicado para extração enzimática foi o cloreto de sódio $(0,9 \%)$. As condições ótimas para extração de celulases, encontradas a partir da metodologia do planejamento experimental, foram: tempo de 35 minutos, temperatura de $40^{\circ} \mathrm{C}$, velocidade de $150 \mathrm{rpm}$, e razão de $11 \mathrm{~mL} / \mathrm{g}$, onde foi previsto pelo modelo uma concentração de 8,5 U/g da enzima em estudo. O modelo proposto para a extração de celulases se mostra bastante confiável a vista dos testes estatísticos de variação baseados na tabela de teste $\mathrm{F}$, sendo avaliado através da ANOVA. Desta forma, a otimização das condições para aumentar a produção desta enzima permite sua futura aplicação nos mais diversos setores industriais.

\section{REFERÊNCIA}

BRASIL, Ministério da Agricultura, do Abastecimento e da Reforma Agrária. Departamento Nacional de Produção Vegetal. Divisão de Sementes e Mudas. Regras para Análise de Sementes. Brasília, 1992. 365p.

CASTILHO, L. R.; ALVES, T. L. M.; MEDRONHO, R. A. Recovery of pectolytic enzymes produced by solid state culture of Aspergillus niger. Process Biochem., v. 34, p. 181-186, 1999.

CASTRO, A. M., \& PEREIRA JR, N. (2010) Produção, propriedades e aplicação de celulases na hidrólise de resíduos agroindustriais. Química Nova 33, 181-188.

ERTAS, M; HAN, Q; CHANG, H. Enzymatic hydrolysis of autohydrolyzed wheat straw followed by refining to produce fermentable sugars. Bioresource Technology 152, 259-266 (2014).

T. K. GHOSE. Measurement Of Cellulase Activities. Pure \& Applied. Chemistry 59, 257-268 (1987).

MACIEL, G. M. Desenvolvimento de bioprocesso para produção de xilanases por fermentação no estado sólido utilizando bagaço de cana de açúcar e farelo de soja. Curitiba-PR: Dissertação de Mestrado UFPR (2006).

MANDELS, M; WEBER, J. Production of cellulases. Advances in Chemistry Series 95, 391-414 (1969).

MURPHYA, L; BOHLIN, C; BAUMANN, MJ; OLSEN, S N; SØRENSEN, T H; ANDERSON, L; BORCH, K; WESTH, P. Product inhibition of five Hypocrea jecorina cellulases. Enzyme and Microbial Technology 52, 163-169 (2013).

WRIGHT, J. D.; WYMAN, C. E.; GROCHMANN, K. Simultaneous saccharification and fermentation of lignocellulose: Process evaluation. Applied Biochemistry and Biotechnology 17, 75-90 (1988). 